\title{
Synthesis and study of the antifungal activity of new mono- and disubstituted derivatives of a genetically engineered polyene antibiotic 28,29-didehydronystatin $A_{1}$ (S44HP)
}

\author{
Maria N Preobrazhenskaya ${ }^{1}$, Eugenia N Olsufyeva ${ }^{1}$, Anna N Tevyashova ${ }^{1}$, Svetlana S Printsevskaya ${ }^{1}$, \\ Svetlana E Solovieva ${ }^{1}$, Marina I Reznikova ${ }^{1}$, Aleksey $S$ Trenin $^{1}$, Olga A Galatenko ${ }^{1}$, Ivan D Treshalin ${ }^{1}$, \\ Eleonora R Pereverzeva ${ }^{1}$, Elena P Mirchink ${ }^{1}$ and Sergey B Zotchev ${ }^{2}$
}

Mono- and disubstituted novel derivatives of the heptaene nystatin analog 28,29-didehydronystatin $A_{1}$ (S44HP, 1) were obtained by chemical modification of the exocyclic C-16 carboxyl and/or an amino group of mycosamine moiety. The strategy of preparation of mono- and double-modified polyene macrolides was based on the use of intermediate hydrophobic $\mathrm{N}$-Fmoc (9-fluorenylmethoxycarbonyl) derivatives that facilitated the procedures of isolation and purification of new compounds. The antifungal activity of the new derivatives was first tested in vitro against yeasts and filamentous fungi, allowing the selection of the most active compounds that were subsequently tested for acute toxicity in mice. 2-(N,N-dimethylamino)ethylamide of 1 (2) and 2-( $N, N$-dimethylamino)ethylamide of $N$-fructopyranosyl-28,29-didehydronystatin $A_{1}(2 a)$ were then selected for further evaluation in a mouse model of disseminated candidosis, and showed high efficacy while being considerably less toxic than amphotericin B (AmB). The compound with improved water solubility (2G, L-glutamic acid salt of 2) showed better chemotherapeutic activity than AmB in the mouse model of candidosis sepsis on a leucopenic background. Very low antifungal effect was seen after treatment with AmB, even if it was used in maximum tolerated dose $\left(2 \mathrm{mg} \mathrm{kg}^{-1}\right)$. Unlike AmB, compound $2 \mathrm{G}$ exhibited high activity in doses from 0.4 up to $4.0 \mathrm{mg} \mathrm{kg}^{-1}$, despite leucopenic conditions.

The Journal of Antibiotics (2010) 63, 55-64; doi:10.1038/ja.2009.118; published online 4 December 2009

Keywords: antifungal polyene macrolide antibiotic; genetically engineered polyene antibiotic 28, 29-didehydro nystatin A1; model of the candidosis sepsis; semi-synthetic macrolide antibiotics

\section{INTRODUCTION}

Systemic fungal infections are becoming increasingly common in modern hospitals. Approximately $40 \%$ of deaths from nosocomial infections are caused by fungi, and $80 \%$ of these are caused by species of Candida and Aspergillus. The frequency of invasive fungal infections has increased with the rise in the number of immunocompromised patients (by disease or because of the use of immunosuppressive agents). ${ }^{1}$ Patients with AIDS caused by human immunodeficiency virus infection, low birthweight infants, neutropenic patients receiving chemotherapy and oncology patients with immune suppression are at an increased risk for invasive fungal infections.

Polyene macrolide amphotericin B (AmB) is the first-line therapy for systemic infection because of its broad spectrum and fungicidal activity. The mechanism of fungicidal action of polyene macriolides is attributed to their binding to ergosterol in the fungal cell membrane, which leads to formation of pores and leakage of ions, resulting in fungal cell death. ${ }^{2}$ However, considerable side effects limit the clinical utility of AmB. Therefore, there is an urgent need to develop new antifungal antibiotics that are efficacious and devoid of toxicity.

Earlier, it was shown that double modifications of polyene macrolides $\mathrm{AmB}^{3-5}$ or partricin $\mathrm{A}^{6}$ improve the biological properties of parent antibiotics. For example, $N$-(1-piperidinepropyl)amphotericin $B$ methyl ester (PAME) was described as a new derivative of AmB with reduced toxicity. ${ }^{3}$ The new semisynthetic derivative of partricin $\mathrm{A}$, SPA-S-753/SPK-843 (N-dimethylaminoacetyl-partricin A 2-dimethylaminoethylamide diascorbate salt), has shown a much higher therapeutic activity and better pharmacological properties than the lipid formulation of $\mathrm{AmB}$, and this agent has reached the clinical stage. 6

Recently, a novel genetically engineered antifungal heptaene nystatin analog, 28,29-didehydronystatin $\mathrm{A}_{1}(\mathrm{~S} 44 \mathrm{HP})^{7}$ (see structure 1 on Scheme 1), was used as a scaffold for chemical modification. ${ }^{8}$

${ }^{1}$ Gause Institute of New Antibiotics, Russian Academy of Medical Sciences, B. Pirogovskaya, 11, Moscow, Russian Federation and ${ }^{2}$ Department of Biotechnology, Norwegian University of Science and Technology, Trondheim, Norway

Correspondence: Dr MN Preobrazhenskaya, Gause Institute of New Antibiotics, Russian Academy of Medical Sciences, B. Pirogovskaya, 11, Moscow 119021, Russian Federation. E-mail: mnp@space.ru

Received 25 August 2009; revised 27 October 2009; accepted 9 November 2009; published online 4 December 2009 


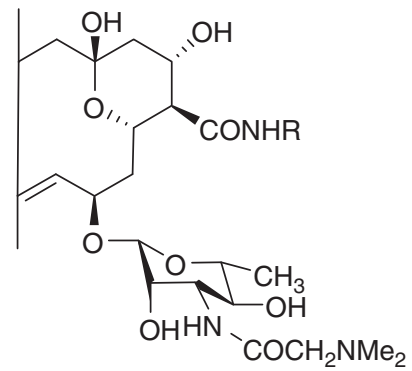

$\mathrm{R}=-\left(\mathrm{CH}_{2}\right)_{2} \mathrm{NMe}_{2}(2 \mathrm{e})$

$\mathrm{R}=-\left(\mathrm{CH}_{2}\right)_{3} \mathrm{NMe}_{2}(\mathrm{ee})$

$\mathrm{R}=-\left(\mathrm{CH}_{2}\right)_{3} \mathrm{OH}(4 \mathrm{e})$

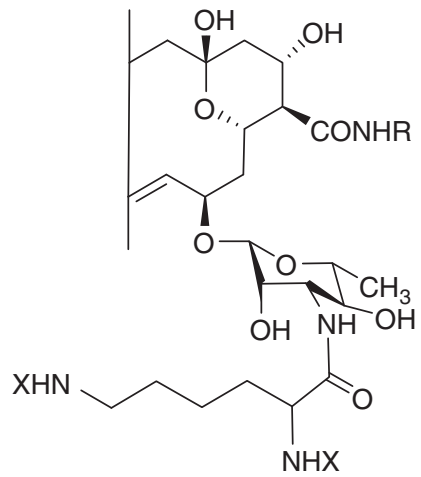

$\mathrm{X}=$ Fmoc; $\mathrm{R}=\left(\mathrm{CH}_{2}\right)_{3} \mathrm{NMe}_{2}$ $\mathrm{X}=\mathrm{H} ; \mathrm{R}=\left(\mathrm{CH}_{2}\right)_{3} \mathrm{NMe}_{2}(3 \mathrm{~d})$

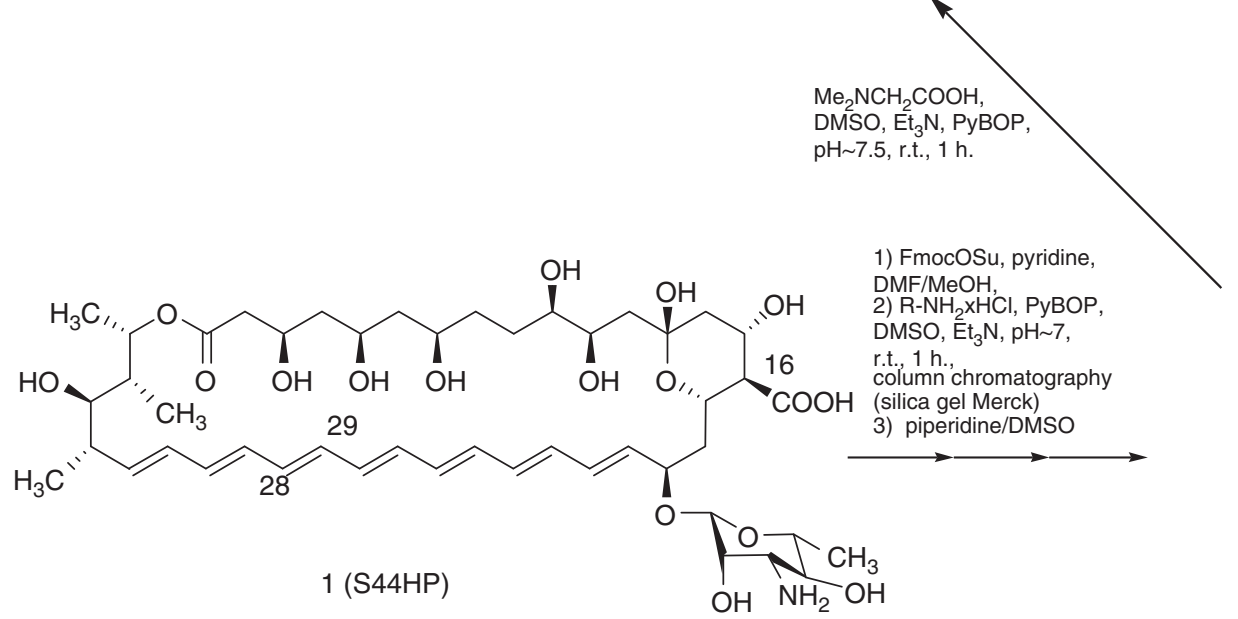

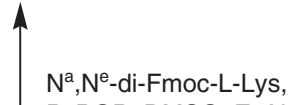
PyBOP, DMSO, $\mathrm{Et}_{3} \mathrm{~N}$, $\mathrm{pH} 7.5$, r.t., 1 h.

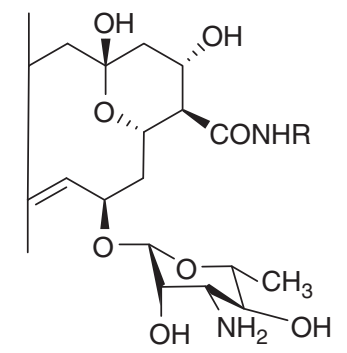

$\mathrm{R}=-\left(\mathrm{CH}_{2}\right)_{2} \mathrm{NMe}_{2}(2)$
$\mathrm{R}=-\left(\mathrm{CH}_{2}\right)_{3} \mathrm{NMe}_{2}(3)$ $\mathrm{R}=-\left(\mathrm{CH}_{2}\right)_{3} \mathrm{OH}(4)$

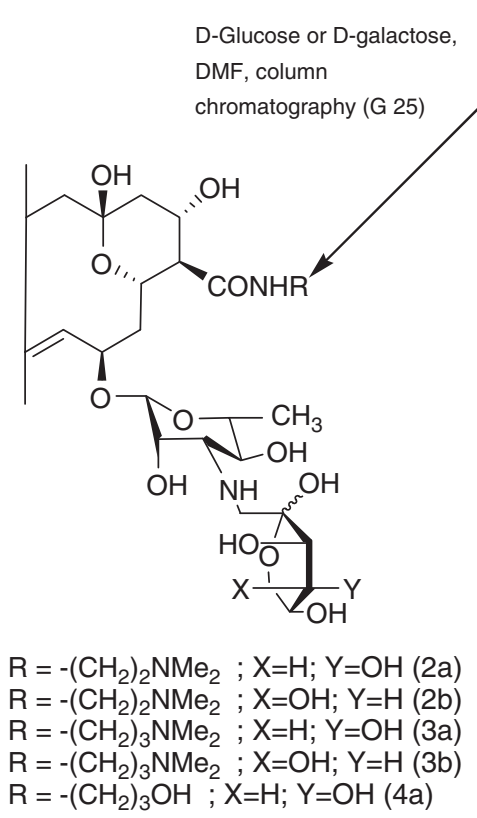

1) $p-\mathrm{Me}_{2} \mathrm{NC}_{6} \mathrm{H}_{4} \mathrm{CHO}$, $\mathrm{NaBH}_{3} \mathrm{CN}$, DMF; 2) Boron resin; 3) column chromatography (silica gel Merck)

$$
\downarrow
$$

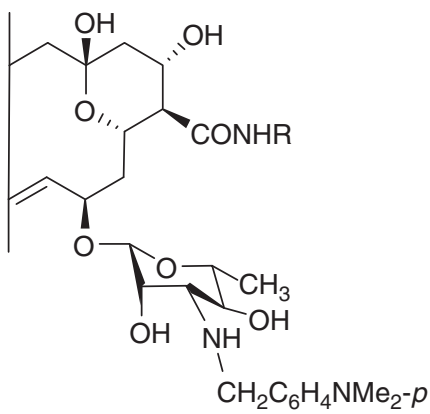

$\mathrm{R}=-\left(\mathrm{CH}_{2}\right)_{2} \mathrm{NMe}_{2}(\mathrm{C} \mathrm{c})$ $\mathrm{R}=-\left(\mathrm{CH}_{2}\right)_{3} \mathrm{NMe}_{2}(3 \mathrm{c})$ $\mathrm{R}=-\left(\mathrm{CH}_{2}\right)_{3} \mathrm{OH}(4 \mathrm{c})$

Scheme 1 Synthesis of the derivatives of 1 (2a-2c, 2e, 3a-3e, $4 a, 4 c$ and $4 e)$ starting from amides (2-4).

Synthesis and structure-activity relationship of 23 new derivatives of 1 modified on the $\mathrm{C} 16-\mathrm{COOH}$ or the $\mathrm{C}^{\prime}-\mathrm{NH}_{2}$ group have been reported. ${ }^{8} 3$-(N,N-dimethylamino)propylamide (DMAP-amide) of 28,29-didehydronystatin $A_{1}$ (3) (Scheme 1) showed the best biological properties. ${ }^{8}$ The in vitro antifungal activities of DMAP-amide against four tested fungal strains were comparable with those of AmB and 1, but the in vivo studies clearly showed superior pharmacological properties of this derivative over AmB. ${ }^{8}$ 
The marked antifungal activity shown by a number of 28,29didehydronystatin $\mathrm{A}_{1}$ derivatives and particularly by the DMAPamide of 28,29-didehydronystatin $A_{1}$ (3) promoted a further structural modification study in our laboratory. On the basis of previously obtained structure-activity relationships, we designed and synthesized derivatives of 1, substituted both at the carboxyl and amino groups, and studied their antifungal activity. The most active compounds were subsequently tested for acute toxicity in mice. High activity and low toxicity of the new compounds, 2-(N,N-dimethylamino)ethylamide of 28,29-didehydronystatin $\mathrm{A}_{1}$ (2) and 2-(N,N-dimethylamino) ethylamide of $N$-fructopyranosyl-28,29-didehydronystatin $A_{1}$ (2a), prompted us to study the antifungal activity of the water-soluble salt of $2(\mathbf{2 G})$ in the model of candidosis sepsis in leucopenic mice.

\section{RESULTS}

\section{Chemistry}

The $N$-9-fluorenylmethoxycarbonyl ( $N$-Fmoc) derivative of $\mathbf{1}$ was used as a key compound in the synthesis of amides 2-(N,N-dimethylamino)ethylamide (DMAE-amide) (2), DMAP-amide (3) and 3-hydroxypropylamide (4). ${ }^{8}$ The corresponding $\mathrm{N}$-Fmoc derivatives of amides 2-4 were purified by column chromatography and deprotected, resulting in amides $\mathbf{2}-\mathbf{4}$ with high purity.

Starting from amides 2 to 4 , the following new double-modified derivatives of $\mathbf{1}$ were obtained: (1) ketosyl derivatives $\mathbf{2 a}, \mathbf{2} \mathbf{b}, \mathbf{3 a}, \mathbf{3} \mathbf{b}$ and $4 \mathbf{a}$ (products of the Amadori rearrangement of $\mathrm{N}$-glycosylderivatives of amides); (2) $\mathrm{N}$-alkyl derivatives $\mathbf{2 c - 4 c}$; and (3) $\mathrm{N}$-aminoacyl derivatives $3 \mathbf{d}, \mathbf{2 e - 4 e}$. The DMAE amide of $N$-fructopyranosyl28,29-didehydronystatin $\mathrm{A}_{1}(\mathbf{2 a})$, the DMAP-amide of $N$-fructopyranosyl-28,29-didehydronystatin $\mathrm{A}_{1}$ (3a), the 3-hydroxypropylamide of $\mathrm{N}$-fructopyranosyl-28,29-didehydronystatin $\mathrm{A}_{1}$ (4a), the DMAEamide of $N$-tagatopyranosyl-28,29-didehydronystatin $\mathrm{A}_{1}(\mathbf{2 b})$ and the DMAP-amide of $N$-tagatopyranosyl-28,29-didehydronystatin $A_{1}(3 \mathbf{b})$ were obtained starting from the corresponding amides $2-4$ and Dglucose or D-galactose according to the procedure described by Preobrazhenskaya et al. ${ }^{8}$ 4-(N,N-dimethylamino)benzyl derivatives 2c, 3c and 4c of amides 2-4 were prepared starting from the corresponding amides 2-4 and 4-(N,N-dimethylamino)benzaldehyde. $\mathrm{N}$-L-lysyl derivative $\mathbf{3} \mathbf{d}$ of amide $\mathbf{3}$ was obtained by acylation reaction starting from amide 3 and $N$-Fmoc-L-lysine in the presence of coupling reagent benzotriazol-1-yloxytripyrrolidino-phosphonium hexafluorophosphate (PyBOP). Deprotection of the intermediate $N$ Fmoc-L-lysyl derivative of $\mathbf{3}$ resulted in $\mathbf{3 d}$. $\mathrm{N}$-( $N, \mathrm{~N}$-dimethylglycyl) derivatives $2 \mathrm{e}-\mathbf{4} \mathbf{e}$ of the corresponding amides $2-\mathbf{4}$ were obtained by the acylation reaction starting from amides $2-4$ and $N, N$-dimethylglycine in the presence of coupling reagent PyBOP. The L-glutamate salt of $2(2 \mathrm{G})$ was prepared to improve water solubility.

$\mathrm{N}$-Fmoc-protected derivatives of $\mathbf{5}$ and $\mathbf{6}$ were used as key compounds in the other approach of the synthesis of disubstituted derivatives (Scheme 2). Acylation of 1 with 4 -( $N$-Fmoc-aminomethyl)benzoic acid in the presence of PyBOP or with $N$-Fmoc-Llysine in the presence of dicyclohexylcarbodiimide/hydroxybenzotriazole resulted in the corresponding $N$-Fmoc-aminoacyl derivatives of $\mathbf{1}$. These intermediates were also transformed into the corresponding N-Fmoc-aminoacyl-28,29-didehydronystatin $\mathrm{A}_{1}$ DMAE-amide, DMAP-amide and 3-hydroxypropylamide, and purified by column chromatography. The target compounds $N$-L-lysyl (2d or $\mathbf{4 d}$ ) and $\mathrm{N}$-(4-aminomethyl)benzoyl derivatives $(\mathbf{2} \mathbf{f}-\mathbf{4 f})$ were isolated after removing the protecting Fmoc group in the presence of piperidine in dimethylsulfoxide (DMSO) (Scheme 2, Table 1). Deprotection of intermediate $\mathrm{N}$-Fmoc-aminoacyl derivatives of 1 yielded a new monosubstituted $N$-(4-aminomethyl)benzoyl derivative (5) (Scheme 2).
Synthesis of $N$-L-lysyl derivative (6) was described earlier in Preobrazhenskaya et al. ${ }^{8}$ The structures of obtained compounds were confirmed by high-resolution mass spectrometry (Table 1) and nuclear magnetic resonance (NMR) spectroscopy (supplementary material).

\section{Biological testing}

Activity of the 19 new derivatives of 1 compared with AmB, parent antibiotic 1 and the earlier obtained amides 3, 4 and $N$-L-lysyl derivative (6) in in vitro tests against yeasts Candida albicans and Cryptococcus humicolus and filamentous fungi (molds) Aspergillus niger and Fusarium oxysporum was investigated. Determination of MICs was carried out as described previously in Preobrazhenskaya et al., ${ }^{8}$ and the results are presented in Tables 2 and 3.

Monomodified amides 3, 4 and the starting 1 were shown to have equal activity against the four investigated fungal strains. Apparently, the new monosubstituted DMAE-amide of 28,29-didehydronystatin $A_{1}$ (2) was twofold more active than 1 against all four strains. The DMAE-amide of $N$-fructopyranosyl-28,29-didehydronystatin $A_{1}$ (2a), the DMAP-amide of $N$-fructopyranosyl-28,29-didehydronystatin $A_{1}$ (3a) and the DMAE-amide of $N$-tagatopyranosyl-28,29-didehydronystatin $A_{1}(\mathbf{2 b})$ were the most active compounds among the disubstituted derivatives of 1 . Their activities were equal ( $\mathrm{MICs}=0.5$ and $1 \mu \mathrm{g} \mathrm{ml}^{-1}$ against $C$. albicans and $A$. niger) or very close (MICs $=1$ and $2 \mu \mathrm{g} \mathrm{ml}^{-1}$ against Cr. humicolus and F. oxysporum) to those of compound 2. In contrast, 3-hydroxypropylamide of $\mathrm{N}$-fructopyranosyl-28,29-didehydronystatin $\mathrm{A}_{1}(\mathbf{4 a})$ showed lower activity against all strains: $\mathrm{MICs}=4$ for $C$. albicans, Cr. humicolus and $A$. niger, and $16 \mu \mathrm{g} \mathrm{ml}^{-1}$ for F. oxysporum.

The activities of 4 -(N,N-dimethylamino)benzyl amides $2 \mathrm{c}, 3 \mathrm{c}$ and $4 \mathbf{c}$ or of $N, N$-dimethylglycylamides $2 \mathbf{e}, 3 \mathbf{e}$ and $4 \mathbf{e}$ were very similar to those of $\mathbf{1}$ or of amides 3 and $\mathbf{4}$ (MICs $\sim 1-2 \mu \mathrm{g} \mathrm{ml}^{-1}$ ) for three strains (C. albicans, Cr. humicolus and A. niger). However, their activities against $F$. oxysporum were rather low $\left(\mathrm{MIC}=16 \mu \mathrm{g} \mathrm{ml}^{-1}\right) . \mathrm{N}$-(4-aminomethyl)benzoyl-28,29-didehydronystatin $\mathrm{A}_{1}$ (5) and $N$-L-lysyl28,29-didehydronystatin $A_{1}$ (6) showed low antifungal activities in vitro in comparison with the parent compound $\mathbf{1}$. It is interesting to note that the secondary modification of antibiotics (transformation of the 16-COOH group into DMAE-amide, DMAP-amide or 3-hydroxypropylamide) in the case of compound $\mathbf{5}$ (yielding compounds $\mathbf{2 f}$, 3f and $\mathbf{4 f}$, correspondingly) almost did not change the activity against all four strains $\left(\mathrm{MIC} \sim 4-16 \mu \mathrm{g} \mathrm{ml}^{-1}\right)$. However, in the case of compound 6 (MIC $\sim 8-16 \mu \mathrm{g} \mathrm{ml}^{-1}$ ), the same secondary modifications (compound $\mathbf{2 d}$, 3d or $\mathbf{4 d}$ ) did improve antifungal activity against all four strains (MIC $\sim 1-4 \mu \mathrm{g} \mathrm{ml}^{-1}$ ).

As compounds 2 and $\mathbf{2 a}$ showed antifungal activities better than $\mathrm{AmB}$ or $\mathbf{1}$ in four tests, they were chosen for in vivo investigations.

Study of the specific activity of $\mathbf{2}$ and $\mathbf{2 a}$ in the mouse model of candidosis was performed as described in the experimental section and in the previous paper by Preobrazhenskaya et al. ${ }^{8}$ The fungal load in kidneys of animals infected with C. albicans (ATCC 14053) and treated with antibiotics was determined and compared with that of untreated animals. Results are presented in Table 4 . The analysis of the results obtained revealed the dose-dependent effect of both studied compounds, and both 2 and $\mathbf{2 a}$ were more effective than AmB, with 2 showing the best activity in vivo. Unlike $\mathrm{AmB}$, treatment using 2 or $\mathbf{2 a}$ in the maximum studied therapeutic doses led to the maximum effect (that is, an almost complete elimination of Candida from kidneys after 4 days of treatment). Compounds 2 and 2 a were almost 10 times less toxic than $\mathrm{AmB}$; for 2a, the highest effective dose was equal to $6 \%$ and for 2 , it was $2 \%$ of the maximum tolerated dose (MTD), whereas AmB had an effective dose equal to $62 \%$ of MTD. 


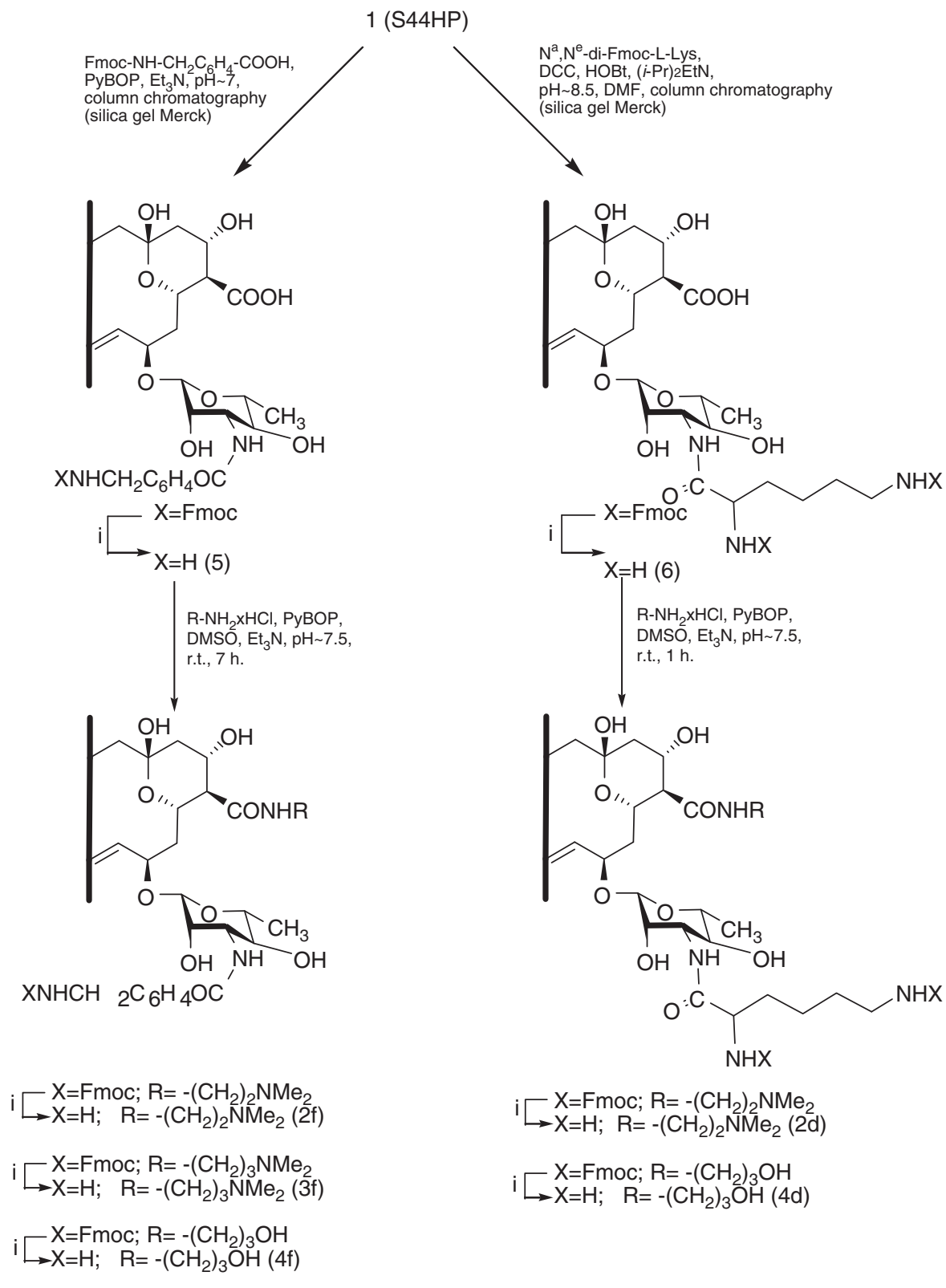

(i): piperidine in DMSO

Scheme 2 Synthesis of the derivatives of $\mathbf{1}(\mathbf{2 f -}-\mathbf{4 f}, \mathbf{2} \mathbf{d}$ and $\mathbf{4 d})$ starting from $\mathrm{N}$-Fmoc-aminoacyl derivatives of $\mathbf{5}$ and $\mathbf{6}$.

Compound 2 showed the best results in this model and it prompted us to prepare water-soluble L-glutamate salt of compound 2 (2G) for the next step of investigations. The antifungal activity of $\mathbf{2 G}$ was very close to the activity of 2 and $\mathrm{AmB}$ in four in vitro tests against C. albicans, Cr. humicolus, A. niger and F. oxysporum.

Acute toxicity of compounds $\mathbf{2}$ and $\mathbf{2 G}$ was studied as described previously in Preobrazhenskaya et al. ${ }^{8} \mathrm{MTD}$ and $\mathrm{LD}_{50}$ values for 2 are $25.9(24.6 \div 27.2) \mathrm{mg} \mathrm{kg}^{-1}$ and $32.2(28.8 \div 35.7) \mathrm{mg} \mathrm{kg}^{-1}$, and for $2 \mathrm{G}$, $14.7(12.8 \div 16.8) \mathrm{mg} \mathrm{kg}^{-1}$ and $22.1(19.3 \div 24.9) \mathrm{mg} \mathrm{kg}^{-1}$, respectively. High solubility and wide therapeutic window (MTD-LD ${ }_{50}$ dose interval) of compound $\mathbf{2 G}$ permitted us to consider it for further investigation in subchronical study.

The multiple-dose toxicity of $\mathbf{2} \mathbf{G}$ and $\mathrm{AmB}$ in male Wistar rats was compared. The animals received $\mathrm{AmB}$ or $\mathbf{2 G}$ i.v. at a daily dose of 0.1 and 0.2 MTD seven times with 48-h intervals. Total doses were equal to MTD and $\mathrm{LD}_{50}$. Compound $2 \mathrm{G}$ showed less pronounced nephrotoxicity and did not influence the quantity of red blood cells and the level of hemoglobin in peripheral blood. The last fact indicates that $\mathbf{2 G}$ has no hemolytic properties. The absence of hemolytic activity was confirmed by microscopic pathology observations, as no significant increase in hemosiderin was observed in the spleen of animals treated with $2 \mathrm{G}$.

To investigate the in vivo efficacy of $\mathbf{2 G}$, a model of candidosis sepsis in leucopenic mice (cyclophosphamide-induced) was used. Leucopenia in animals, induced by cyclophosphamide, is one of the immunosuppression models. For these mice, we adapted the technical procedure described in Takemoto et al..$^{9}$ A very low antifungal effect was seen after the treatment with $A m B$, even if the antibiotic was used 
Table 1 Physicochemical properties of the derivatives of $1^{\text {a }}$

\begin{tabular}{|c|c|c|c|c|c|c|}
\hline Compound & Molecular formula & $T L C\left(R_{\mathrm{F}}\right)^{\mathrm{a}}$ & $\operatorname{HPLC}\left(R_{t}\right)^{\mathrm{b}}$ & Purity (percentage of the main peak) & MS (calculated) & $M S$ (found): $[\mathrm{M}+\mathrm{Na}]^{+1_{\mathrm{c}}}$ \\
\hline \multicolumn{7}{|c|}{ Monosubstituted derivatives of 1} \\
\hline 2 & $\mathrm{C}_{51} \mathrm{H}_{83} \mathrm{~N}_{3} \mathrm{O}_{16}$ & $0.24(1)$ & $10.70(A)$ & 97.6 & 993.61 & 1016.58 \\
\hline 5 & $\mathrm{C}_{55} \mathrm{H}_{80} \mathrm{~N}_{2} \mathrm{O}_{18}$ & $0.24(I)$ & $14.52(A)$ & 97.0 & 1056.54 & 1079.44 \\
\hline \multicolumn{7}{|c|}{ Disubstituted derivatives of 1} \\
\hline $2 a^{d}$ & $\mathrm{C}_{57} \mathrm{H}_{93} \mathrm{~N}_{3} \mathrm{O}_{21}$ & $0.53(I I I)$ & $14.92(D)$ & 98.1 & 1155.63 & 1178.55 \\
\hline $2 b$ & $\mathrm{C}_{57} \mathrm{H}_{93} \mathrm{~N}_{3} \mathrm{O}_{21}$ & $0.52(\mathrm{II})$ & $11.00(\mathrm{~A})$ & 97.2 & 1155.63 & $1156.47^{e}$ \\
\hline 2c & $\mathrm{C}_{60} \mathrm{H}_{94} \mathrm{~N}_{4} \mathrm{O}_{16}$ & $0.51(\mathrm{II})$ & $14.69(A)$ & 95.7 & 1126.67 & 1149.57 \\
\hline $2 d$ & $\mathrm{C}_{57} \mathrm{H}_{95} \mathrm{~N}_{5} \mathrm{O}_{17}$ & $0.02(\mathrm{I})$ & $8.50(\mathrm{C})$ & 96.3 & 1121.67 & $1122.49^{e}$ \\
\hline $2 \mathrm{e}$ & $\mathrm{C}_{55} \mathrm{H}_{90} \mathrm{~N}_{4} \mathrm{O}_{17}$ & 0.29 (II) & $11.43(\mathrm{~A})$ & 97.1 & 1078.63 & $1079.41^{\mathrm{e}}$ \\
\hline $2 f$ & $\mathrm{C}_{59} \mathrm{H}_{90} \mathrm{~N}_{4} \mathrm{O}_{17}$ & $0.01(\mathrm{I})$ & $12.10(A)$ & 95.5 & 1126.63 & 1149.56 \\
\hline $3 a$ & $\mathrm{C}_{58} \mathrm{H}_{95} \mathrm{~N}_{3} \mathrm{O}_{21}$ & $0.57(\mathrm{III})$ & $14.07(B)$ & 97.1 & 1169.65 & 1192.63 \\
\hline $3 b$ & $\mathrm{C}_{58} \mathrm{H}_{95} \mathrm{~N}_{3} \mathrm{O}_{21}$ & $0.53(\mathrm{II})$ & $12.21(\mathrm{~A})$ & 96.3 & 1169.65 & 1192.47 \\
\hline $3 c$ & $\mathrm{C}_{61} \mathrm{H}_{96} \mathrm{~N}_{4} \mathrm{O}_{16}$ & $0.55(I I)$ & $24.78(B)$ & 96.0 & 1140.68 & 1163.65 \\
\hline $3 d$ & $\mathrm{C}_{58} \mathrm{H}_{97} \mathrm{~N}_{5} \mathrm{O}_{17}$ & $0.02(\mathrm{I})$ & $9.98(A)$ & 95.1 & 1135.69 & 1158.73 \\
\hline $3 e$ & $\mathrm{C}_{56} \mathrm{H}_{92} \mathrm{~N}_{4} \mathrm{O}_{17}$ & $0.20(\mathrm{II})$ & $11.49(\mathrm{~A})$ & 95.6 & 1092.65 & 1115.41 \\
\hline $3 f$ & $\mathrm{C}_{60} \mathrm{H}_{92} \mathrm{~N}_{4} \mathrm{O}_{17}$ & $0.01(\mathrm{I})$ & $11.98(A)$ & 95.4 & 1140.68 & $1141.54^{\mathrm{e}}$ \\
\hline $4 a$ & $\mathrm{C}_{56} \mathrm{H}_{90} \mathrm{~N}_{2} \mathrm{O}_{22}$ & 0.57 (III) & $13.22(A)$ & 96.0 & 1142.6 & 1165.58 \\
\hline $4 c$ & $\mathrm{C}_{59} \mathrm{H}_{91} \mathrm{~N}_{3} \mathrm{O}_{17}$ & $0.53(\mathrm{II})$ & $18.25(\mathrm{~A})$ & 95.9 & 1113.63 & 1136.53 \\
\hline $4 d^{d}$ & $\mathrm{C}_{56} \mathrm{H}_{92} \mathrm{~N}_{4} \mathrm{O}_{18}$ & $0.01(\mathrm{I})$ & $9.93(A)$ & 95.4 & $1108.64^{\mathrm{e}}$ & $1109.49^{e}$ \\
\hline $4 \mathrm{e}$ & $\mathrm{C}_{54} \mathrm{H}_{87} \mathrm{~N}_{3} \mathrm{O}_{18}$ & $0.47(I I)$ & $13.10(\mathrm{~A})$ & 97.5 & 1065.60 & $1070.49^{f}$ \\
\hline $4 f$ & $\mathrm{C}_{58} \mathrm{H}_{87} \mathrm{~N}_{3} \mathrm{O}_{18}$ & $0.2(\mathrm{I})$ & $14.03(A)$ & 95.8 & 1113.63 & 1136.57 \\
\hline
\end{tabular}

TLC was carried out on Merck Silica Gel $60 \mathrm{~F}_{254}$ plates in the following solvent systems: (I) $\mathrm{CHCl}_{3}: \mathrm{MeOH}_{\mathrm{H}} \mathrm{H} \mathrm{O}: \mathrm{HCOOH}$ (13:6:1:0.1), (II) $\mathrm{CHCl} 3: \mathrm{MeOH}^{\mathrm{H}} \mathrm{H}_{2} \mathrm{O}: \mathrm{NH}_{4} \mathrm{OH}$ (conc.) (13:6:0.7:0.01), (III) AcOEt:n-ProOH: $\mathrm{NH}_{4} \mathrm{OH}$ (conc.) (15:10:10).

bHPLC was carried out on a Shimadzu HPLC instrument of the LC 10 series on a Kromasil $100-C 18$ column $(4 \times 250 \mathrm{~mm}$, particle size $6 \mu \mathrm{m})$ at an injection volume of $20 \mu \mathrm{l}$ and a wavelength of

$408 \mathrm{~nm}$ with a flow rate of $1.0 \mathrm{ml} \mathrm{min}^{-1}$. The system compared $0.2 \% \mathrm{HCOONH}_{4}(\mathrm{pH} 4.5)$ with acetonitrile. The proportion of acetonitrile was varied from $30 \%$ to $70 \%$ for $30 \mathrm{~min}$ (system $\mathrm{A}$ );

from $25 \%$ to $65 \%$ for $40 \mathrm{~min}$ (system B); from $30 \%$ to $90 \%$ for $30 \mathrm{~min}$ (system C); isocratic system-35\% of acetonitrile (system D).

${ }^{c}$ Mass spectral data were obtained on MALDI TOF Bruker BIFLEX III instrument.

${ }^{\mathrm{d}}$ Hydrochloride salt.

$\mathrm{e}[\mathrm{M}+\mathrm{H}]^{+1}$.

$\mathrm{f}\left[\mathrm{M}-\mathrm{H}_{2} \mathrm{O}+\mathrm{Na}\right]^{+1}$

in MTD $\left(2 \mathrm{mg} \mathrm{kg}^{-1}\right)$. Unlike $\mathrm{AmB}$, compound $2 \mathrm{G}$ showed high activity in doses from 0.4 to $4.0 \mathrm{mg} \mathrm{kg}^{-1}$, despite leucopenic conditions. The results are presented in Figure 1.

\section{DISCUSSION}

Chemical modification of polyene macrolide antibiotics leads to serious problems that stem from the high molecular weight of these compounds, their poor solubility in common organic solvents, as well as their high chemo- and photosensitivities and formation of aggregates that seriously hamper the processes of isolation and purification. Our synthetic strategy was based on the use of intermediate polyene derivatives containing a hydrophobic protecting group that increases the stability and facilitates column chromatographic purification of these compounds. We selected the Fmoc protecting group, as this type of derivatization led to the formation of polyene derivatives suitable for purification, and de-blocking conditions were not harmful for the antibiotic structure.

The in vitro experiments showed high activities (MIC $1-2 \mu \mathrm{g} \mathrm{ml}^{-1}$ ) against $C$. albicans, Cr. humicolus and A. niger and moderate activities against $F$. oxysporum (MIC $\sim 4-16 \mu \mathrm{g} \mathrm{ml}^{-1}$ ) (Tables 2 and 3 ) for all disubstituted derivatives of $\mathbf{1}$. The monosubstituted derivative $\mathbf{2}$ and the disubstituted derivatives $\mathbf{2} \mathbf{a}$ and $\mathbf{2} \mathbf{b}$ were the best in in vitro tests. Compounds $\mathbf{2}$ and $\mathbf{2 a}$ were chosen for in vivo experiments.

It was shown that $\mathbf{2}$ and $\mathbf{2 a}$ were clearly superior to $A m B$ in terms of both toxicity and therapeutic efficacy in mouse models (Table 4).
We also compared antifungal activities and toxicity properties of derivatives with very close chemical structures-compounds 2 and 3. The MTD-LD 50 dose interval for $2\left(\mathrm{MTD}=25.9(24.6 \div 27.2) \mathrm{mg} \mathrm{kg}^{-1}\right.$ and $\left.\mathrm{LD}_{50}=32.2(28.8 \div 35.7) \mathrm{mg} \mathrm{kg}^{-1}\right)$ (Table 4) was slightly better than that for $3\left(\mathrm{MTD}=11.9(10.3 \div 13.6) \mathrm{mg} \mathrm{kg}^{-1}\right.$ and $\mathrm{LD}_{50}=16.4$ $\left.(13.9 \div 18.9) \mathrm{mg} \mathrm{kg}^{-1}\right){ }^{8}$ The differences in toxicity and antifungal activity for compounds 2 and 3 can be explained by the difference in their chemical structure.

Derivative $\mathbf{2}$ and its water-soluble L-glutamate salt $\mathbf{2 G}$ showed equal in vitro activities against four tested strains. The model of candidosis sepsis in leucopenic mice (cyclophosphamide-induced) was used to investigate the in vivo efficacy of $\mathbf{2 G}$. It is important to mention that systemic fungal infections are especially dangerous for patients whose immune system is compromised. It was shown that $\mathbf{2 G}$ was clearly superior to AmB in terms of both toxicity and therapeutic efficacy in mouse models (Figure 1).

The MTD-LD ${ }_{50}$ dose interval for water-soluble $2 \mathrm{G}$ (MTD= $14.7(12.8 \div 16.8) \mathrm{mg} \mathrm{kg}^{-1}$ and $\left.\mathrm{LD}_{50}=22.1(19.3 \div 24.9) \mathrm{mg} \mathrm{kg}^{-1}\right)$ was slightly better in comparison with compound 2 .

Hence, we generated a series of new semisynthetic polyene macrolides, and demonstrated that derivatives $\mathbf{2}$, its L-glutamate salt $\mathbf{2 G}$ and 2a have advantages over AmB in terms of both toxicity and therapeutic efficacy in mouse models. The high solubility and wide therapeutic window of compound $\mathbf{2 G}$, together with high chemotherapeutic activity in the mouse model of candidosis sepsis on a leucopenic background, give hope that we are on the way to developing a new, safe and efficient antifungal drug for human use. 
Table 2 Antifungal activity of dimodified derivatives $2 a-2 c, 2 e, 3 a-3 c, 3 e, 4 a, 4 c$ and $4 e$ in comparison with monosubstituted derivatives 2 , $3,4, \mathrm{AmB}$ and 1

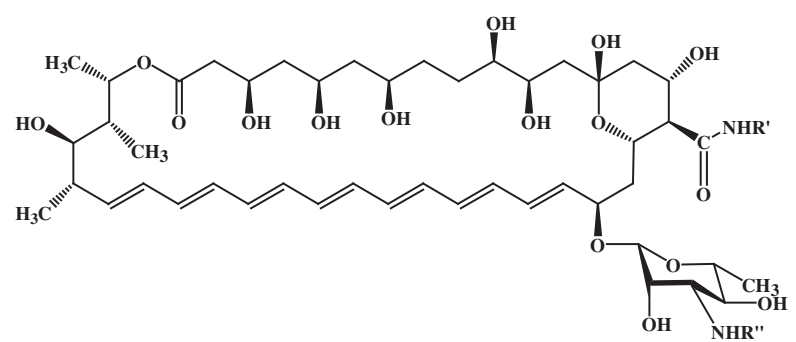

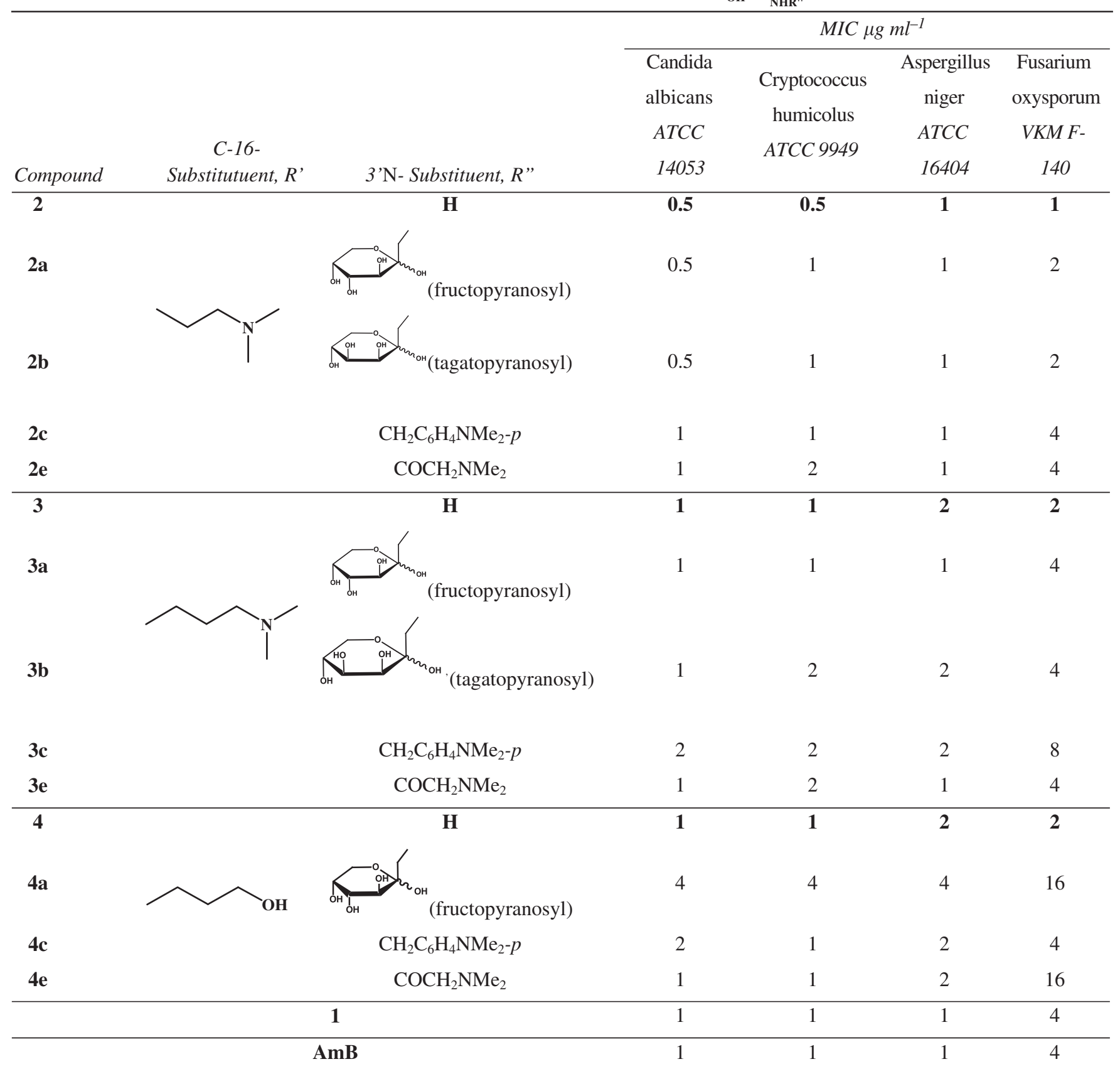

Abbreviation: $\mathrm{AmB}$, amphotericin $\mathrm{B}$. 


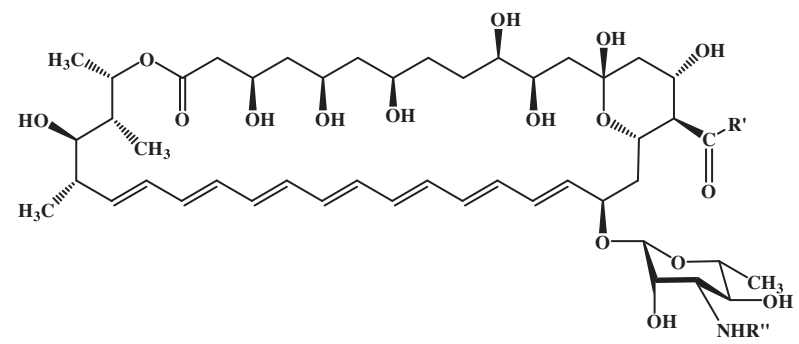

\begin{tabular}{|c|c|c|c|c|c|c|}
\hline \multirow[b]{4}{*}{ Compound } & \multirow[b]{4}{*}{$\begin{array}{c}\text { 3’N-substituent, } \\
R ”\end{array}$} & \multirow[b]{4}{*}{$\begin{array}{c}C-16-\text { Substituent, } \\
R^{\prime}\end{array}$} & \multicolumn{4}{|c|}{$M I C \mu g m l^{-1}$} \\
\hline & & & Candida & Cryptococcus & Aspergillus & Fusarium \\
\hline & & & albicans & humicolus & niger & oxysporum \\
\hline & & & АТCC 14053 & АТСС 9949 & АТСС 16404 & $V K M F-140$ \\
\hline 5 & & $\mathrm{OH}$ & 2 & 2 & 4 & 16 \\
\hline $2 f$ & & & 2 & 2 & 2 & 4 \\
\hline $3 f$ & & & 2 & 2 & 4 & 4 \\
\hline $4 f$ & & $-\mathrm{HN}^{\prime}$ & 2 & 2 & 4 & 16 \\
\hline 6 & $\mathrm{H}_{2} \mathrm{~N}_{-}$ & $\mathrm{OH}$ & 8 & 8 & 16 & $>16$ \\
\hline $2 d$ & & & 1 & 2 & 2 & 4 \\
\hline 3d & & & 1 & 1 & 1 & 2 \\
\hline $4 d$ & $\mathrm{NH}_{2}$ & & 1 & 1 & 2 & 4 \\
\hline
\end{tabular}

\section{METHODS}

\section{General experimental procedures}

Polyene macrolide 1 was produced and purified as described in Preobrazhenskaya et al. ${ }^{8}$ TLC was carried out on Merck Silica Gel $60 \mathrm{~F}_{254}$ plates (Merck, Whitehouse Station, NJ, USA) in the following solvent systems: (I) $\mathrm{CHCl}_{3}: \mathrm{MeOH}: \mathrm{H}_{2} \mathrm{O}: \mathrm{HCOOH}$ (13:6:1:0.1), (II) $\mathrm{CHCl}_{3}: \mathrm{MeOH}: \mathrm{H}_{2} \mathrm{O}: \mathrm{NH}_{4} \mathrm{OH}$ (conc.) (13:6:0.7:0.01), (III) AcOEt: $n$-ProOH: $\mathrm{NH}_{4} \mathrm{OH}$ (conc.) (15:10:10). Spots were detected by sight and by using a UV lamp at $254 \mathrm{~nm}$. HPLC was carried out on a Shimadzu HPLC instrument (Shimadzu, Kyoto, Japan) of the LC 10 series (Shimadzu) on a Kromasil 100-C18 column (Kromasil; $4 \times 250 \mathrm{~mm}$, particle size, $6 \mu \mathrm{m}$ ) at an injection volume of $20 \mu \mathrm{l}$ (concentration of samples was $0.02-0.03 \mathrm{mg} \mathrm{ml}^{-1}$ ) and at a wavelength of $408 \mathrm{~nm}$ with a flow rate of $1.0 \mathrm{ml} \mathrm{min}^{-1}$. The system compared $0.2 \% \mathrm{HCOONH}_{4}(\mathrm{pH} 4.5)$ with acetonitrile. The proportion of acetonitrile varied from 30 to $70 \%$ for $30 \mathrm{~min}$ (system A); from 25 to $65 \%$ for $40 \mathrm{~min}$ (system B); from 30 to $90 \%$ for $30 \mathrm{~min}$ (system C); isocratic system-35\% of acetonitrile (system D). ${ }^{1} \mathrm{H}-\mathrm{NMR}$ spectra were recorded on a Varian VXR-400 NMR spectrometer (Varian, Palo Alto, CA, USA) at $35^{\circ} \mathrm{C}$ and referenced to TMS, observing protons at $400 \mathrm{Mhz}$. Mass spectra determined by matrix-assisted laser desorption/ionization (MALDI) were recorded on Brucker BIFLEX III (Brucker, Bremen, Germany). Data for the predominant monoisotope peak are presented. All solutions were dried over sodium sulfate and evaporated at reduced pressure on a Buchi rotary evaporator (Buchi, Flawil, Switzerland) at a temperature below $35^{\circ} \mathrm{C}$. 
Table 4 In vivo MTD and antifungal activity of 2 and 2a compared with AmB tested in mouse model of disseminated candidosis

\begin{tabular}{lccc}
\hline & \multicolumn{2}{c}{ MTD } & \\
\cline { 2 - 3 } Compound & $m g \mathrm{~kg}^{-1}$ per day & $\mathrm{mg} \mathrm{kg}^{-1}$ per day & (ED/MTD, \%) \\
\hline AmB & 2.01 & 1.25 & 62 \\
$\mathbf{2 a}$ & 21.2 & 1.25 & 6 \\
$\mathbf{2}$ & 25.9 & 0.62 & 2 \\
\hline
\end{tabular}

Abbreviations: AmB, amphotericin B; ED, effective dose; MTD, maximum tolerated dose.

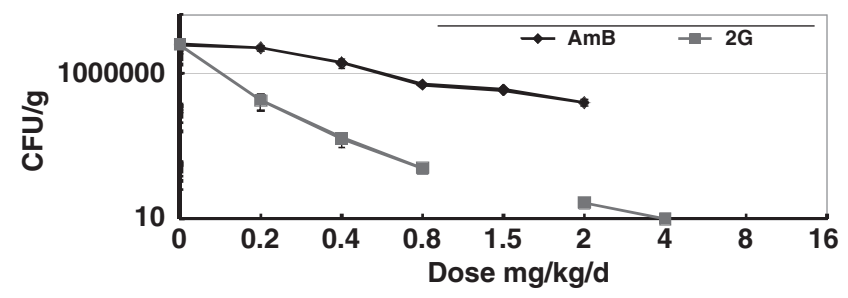

Figure $\mathbf{1}$ Chemotherapeutic activity of $\mathbf{2 G}$ (L-glutamate salt of 2 ) and AmB in mice pretreated with cyclophosphamide.

\section{2-(N,N-dimethylamino)ethylamide (2), 3-(N,N-dimethylamino) propylamide (3) and 3-hydroxypropylamide (4) of 1}

Derivatives were obtained in three steps according to the conditions described earlier by Preobrazhenskaya et al. ${ }^{8}$ (method B) starting from 1 . The yields of all amides were about $55-60 \%$.

\section{L-glutamate salt of 2-(N,N-dimethylamino)ethylamide of 1 (2G)} Amide $2(200 \mathrm{mg}, 0.2 \mathrm{mmol})$ was dissolved in DMSO $(5 \mathrm{ml})$ and the solution of L-glutamic acid $(29.4 \mathrm{mg}, 0.2 \mathrm{mmol})$ in $\mathrm{H}_{2} \mathrm{O}(2 \mathrm{ml})$ was added. The mixture was kept at room temperature for $15 \mathrm{~min}$. Addition of diethyl ether $(6 \mathrm{ml})$ to the mixture led to an oily residue, which was shaken successively with diethyl ether $(3 \times 6 \mathrm{ml})$. After addition of $10 \mathrm{ml}$ of acetone to this oil, a yellow precipitate of salt was formed. The precipitate was filtrated, washed by acetone and then dried in vacuo, yielding $210 \mathrm{mg}$ of $2 \mathrm{G}$ (yield $92 \%$, purity $97.8 \%$, $R_{\mathrm{t}}=10.48$, system A).

\section{$\mathrm{N}$-ketosyl derivatives (products of Amadori rearrangement) of amides (2a, 2b, 3a, 3b and 4a)}

All derivatives were obtained as per the method described in Preobrazhenskaya et al., ${ }^{8}$ starting from the corresponding amide 2,3 or $4(0.1 \mathrm{mmol})$ and a monosaccharide (D-glucose or D-galactose) $(0.8 \mathrm{mmol})$ in dimethylformamide. The obtained crude compounds $\mathbf{2} \mathbf{a}, \mathbf{2} \mathbf{b}, \mathbf{3} \mathbf{a}, \mathbf{3} \mathbf{b}$ and $\mathbf{4 a}$ were purified by column chromatography on Sephadex G-25 (Pharmacia Fine Chemicals AB, Uppsala, Sweden). Column chromatography was carried out using water. The purity of the fraction was controlled by TLC (system III). Fractions containing the desired compound were collected and the solution was concentrated. The addition of acetone resulted in a yellow precipitate, which was filtered off, washed with acetone and dried in vacuo. The compound 2a was obtained as a hydrochloride by adding $0.1 \mathrm{~N} \mathrm{HCl} /$ methanol at $\mathrm{pH} \sim 4$ to the solution of $2 \mathrm{a}$ in methanol. The addition of diethyl ether resulted in a yellow precipitate, which was filtered off, washed with diethyl ether and dried in vacuo. The yields of pure compounds $\mathbf{2 a}, \mathbf{2} \mathbf{b}, \mathbf{3} \mathbf{a}, \mathbf{3} \mathbf{b}$ and $\mathbf{4 a}$ were about $30-40 \%$.

\section{$\mathrm{N}$-alkyl derivatives of amides of 1 (2c, 3c and 4c)}

$\mathrm{N}$-alkyl derivatives were obtained according to the method described by Preobrazhenskaya et al., ${ }^{8}$ starting from the appropriate amide 2,3 or 4 (0.1 mmol), 4 -(N,N-dimethylamino)benzaldehyde $(0.4 \mathrm{mmol})$ and $\mathrm{NaBH}_{3} \mathrm{CN}$ $(0.4 \mathrm{mmol})$ in dimethylformamide. The yields of pure compounds $2 \mathrm{c}, 3 \mathrm{c}$ and $4 \mathrm{c}$ were about $50-60 \%$.
$N$-L-lysyl- $N, N$-dimethylaminopropyl amide of 1 (3d)

To a solution of amide $3(50 \mathrm{mg}, 0.05 \mathrm{mmol})$ in DMSO (1 ml), $N^{\alpha}, N^{\varepsilon}$-di-FmocL-lysine $(60 \mathrm{mg}, 0.1 \mathrm{mmol})$ and $\mathrm{Et}_{3} \mathrm{~N}$ were added $(\mathrm{pH} 7)$, after which PyBOP ( $39 \mathrm{mg}, 0.075 \mathrm{mmol}$ ) was added to this mixture for $15 \mathrm{~min}$. The reaction mixture was stirred at room temperature for $1 \mathrm{~h}$. Subsequent addition of diethyl ether $(\sim 5 \mathrm{ml})$ to the reaction mixture led to an oily residue, which was shaken successively with diethyl ether $(5 \mathrm{ml} \times 2)$. After the addition of $5 \mathrm{ml}$ of acetone to this oil, a yellow precipitate of amide was formed. The precipitate was filtrated, washed with acetone and then dried in vacuo yielding $50 \mathrm{mg}$ $N$-( $N^{\alpha}, N^{\varepsilon}$-di-Fmoc-L-lysyl)- $N, N$-dimethylaminopropyl amide of $\mathbf{1}$ with a purity of $95 \%$, on the basis of HPLC data $\left(R_{\mathrm{t}}=22.01\right.$, system B). The removal of Fmoc groups was carried out according to the method described in Preobrazhenskaya et al. ${ }^{8}$ for $\mathrm{N}$-aminoacyl derivative using the excess of piperidine in DMSO yielding the target product $3 \mathrm{~d}$ (38 mg, 60\%).

$\mathrm{N}$-aminoacyl derivatives of amides of $1(2 e, 3 e$ and $4 e)$

Derivatives were synthesized starting from the corresponding amides 2,3 or 4 $(0.05 \mathrm{mmol}), N, N$-dimethylglycine $(0.1 \mathrm{mmol})$ and PyBOP $(0.075 \mathrm{mmol})$ in DMSO as described above for $3 \mathbf{d}$, and a yield of about $60-70 \%$ was obtained.

\section{$\mathrm{N}$-aminoacyl derivatives of amides of 1 (2d, 4d)}

To a solution of $N^{\alpha}, N^{\varepsilon}$-di-(9-fluorenylmethoxycarbonyl)-L-lysine $(180 \mathrm{mg}$, $0.33 \mathrm{mmol}$ ), cooled to $\sim+5{ }^{\circ} \mathrm{C}, \mathrm{N}$-hydroxybenzotriazole $(54 \mathrm{mg}, 0.4 \mathrm{mmol})$ in dry dimethylformamide $(1.2 \mathrm{ml})$ and dicyclohexylcarbodiimide $(62 \mathrm{mg}$, $0.3 \mathrm{mmol}$ ) were added, and the reaction mixture was stirred at $\sim 5^{\circ} \mathrm{C}$ for $1 \mathrm{~h}$. The residue of DCU was filtered and the obtained eluate was added to the solution of $1(184 \mathrm{mg}, 0.2 \mathrm{mmol})$ in dimethylformamide $(1 \mathrm{ml})$. (i-Pr) $)_{2} \mathrm{EtN}$ $(0.1 \mathrm{ml}, 0.81 \mathrm{mmol})$ was added to the reaction mixture dropwise for $10 \mathrm{~min}$, under constant stirring. The reaction mixture was stirred at room temperature for $2 \mathrm{~h}$ (TLC control in the solvent system $\mathrm{CHCl}_{3}: \mathrm{MeOH}: \mathrm{H}_{2} \mathrm{O}: \mathrm{HCOOH}$ (6:1:0.01:0.02)), and then diethyl ether $(20 \mathrm{ml})$ was added. The obtained precipitate was filtered off, washed using the mixture of diethyl ether-acetone (1:1) $(10 \mathrm{ml} \times 3)$ and dried in vacuum, yielding $202 \mathrm{mg}$ of yellow powder. The crude compound was purified by column chromatography on silica gel (Merck). Column chromatography was performed using the solvent system $\mathrm{CHCl}_{3}: \mathrm{MeOH}: \mathrm{H}_{2} \mathrm{O}: \mathrm{HCOOH}$ (9:1:0.01:0.02 $\rightarrow$ 7:1:0.01:0.02). The purity of the fraction was controlled by TLC. Fractions containing the desired compound were collected and the solution was concentrated. The addition of acetone resulted in a yellow precipitate, which was filtered off, washed with acetone and dried in vacuo, yielding $60 \mathrm{mg}$ of pure $N$ - $\left(N^{\alpha}, N^{\varepsilon}\right.$-di-(9-fluorenylmethoxycarbonyl)-L-lysyl)-28,29-didehydronystatin $\mathrm{A}_{1}$ (HPLC $96 \%, R_{\mathrm{t}}=22.80$, system $\mathrm{B}$ ). Subsequent amidation of Fmoc-protected derivative by the corresponding amine hydrochloride (3-( $N, N$-dimethylamino)ethylamine or 3-hydroxypropylamine) was performed as described in Preobrazhenskaya et al. ${ }^{8}$ (method A). The removal of Fmoc groups from the resulting derivatives was carried out according to the method described by Preobrazhenskaya et al., ${ }^{8}$ giving a total yield of 15 and $20 \%$ of the desired products $2 \mathbf{d}$ and $\mathbf{4 d}$, respectively.

\section{$\mathrm{N}$-L-lysyl-28,29-didehydronystatin $\mathrm{A}_{1}(6)$}

Monosubstituted derivative 6 was obtained from the intermediate $N-\left(N^{\alpha}, N^{\varepsilon_{-}}\right.$ di-(9-fluorenylmethoxycarbonyl)-L-lysyl-28,29-didehydronystatin $A_{1}$, as described in Preobrazhenskaya et al. ${ }^{8}$

\section{Amides of $\mathrm{N}$-4-aminomethylbenzoyl-28,29-didehydronystatin} $A_{1}(2 f, 3 f$ and $4 f)$

To a solution of 4 - $(\mathrm{N}$-Fmoc-aminomethyl)benzoic acid $(246 \mathrm{mg}, 0.66 \mathrm{mmol})$ and $1\left(300 \mathrm{mg}, 0.33 \mathrm{mmol}\right.$ ) in DMSO $(10 \mathrm{ml}), \mathrm{Et}_{3} \mathrm{~N}$ (to adjust $\mathrm{pH} 7$ ) and PyBOP $(206 \mathrm{mg}, 0.396 \mathrm{mmol})$ were added. The reaction mixture was kept at room temperature for $6 \mathrm{~h}$ and then added dropwise to diethyl ether $(200 \mathrm{ml})$. The yellow precipitate was filtered off and purified by column chromatography on Merck Silica Gel $(0.040-0.063 \mathrm{~mm}$; Merck $)$ in the solvent system $\mathrm{CHCl}_{3}: \mathrm{MeOH}: \mathrm{HCOOH}$ (3:1:0.01) to yield $N$-(4-N-Fmoc-aminomethyl)benzoyl-28,29-didehydronystatin $\mathrm{A}_{1}(130 \mathrm{mg}, 31 \%)$ with a purity of $95 \%$ by HPLC data $\left(R_{\mathrm{t}}=18.18\right.$, system $\left.\mathrm{B}\right)$ and TLC data $\left(R_{\mathrm{F}}=0.61\right.$, system $\left.\mathrm{I}\right)$.

Amidation of $\mathrm{N}$-(4-N-Fmoc-aminomethyl)benzoyl-28,29-didehydronystatin $A_{1}$ was performed as described in Preobrazhenskaya et al. ${ }^{8}$ (method A), 
starting from $\mathrm{N}$-(4-Fmoc-aminomethylbenzoyl)-28,29-didehydronystatin $\mathrm{A}_{1}$ $(0.03 \mathrm{mmol})$ and appropriate amine hydrochlorides $(0.12 \mathrm{mmol})$ in the presence of PyBOP reagent $(0.045 \mathrm{mmol})$. The reaction mixture was stirred for $7 \mathrm{~h}$. HPLC data: ( $N, N$-dimethylamino)propyl amide of $N$-(4-Fmoc-aminomethylbenzoyl)-28,29-didehydronystatin $\mathrm{A}_{1}\left(R_{\mathrm{t}}=15.88\right.$, system $\mathrm{B} ; R_{\mathrm{F}}=0.25$, system I), hydroxypropylamide of $\mathrm{N}$-(4-Fmoc-aminomethylbenzoyl)-28,29-didehydronystatin $\mathrm{A}_{1}\left(R_{\mathrm{t}}=17.14\right.$, system $\mathrm{B} ; R_{\mathrm{F}}=0.60$, system $\left.\mathrm{I}\right)$ and $(N, N$-dimethylamino)ethyl amide of $\mathrm{N}$-(4-Fmoc-aminomethylbenzoyl)-28,29-didehydronystatin $\mathrm{A}_{1}\left(R_{\mathrm{t}}=15.95\right.$, system $\mathrm{B} ; R_{\mathrm{F}}=0.24$, system $\left.\mathrm{I}\right)$.

Deprotection was carried out according to the conditions described in Preobrazhenskaya et al., ${ }^{8}$ yielding $N$-4-aminomethylbenzoyl amides $2 \mathbf{f}, 3 \mathbf{3 f}$ and $\mathbf{4 f}$ (yield $\sim 80 \%$; purity $>95 \%$ ).

$\mathrm{N}$-(4-aminomethylbenzoyl)-28,29-didehydronystatin $\mathrm{A}_{1}$ (5)

$\mathrm{N}$-(4-aminomethylbenzoyl)-28,29-didehydronystatin $\mathrm{A}_{1}(\mathbf{5})$ was obtained from the intermediate $\mathrm{N}$-(4-N-Fmoc-aminomethyl)benzoyl-28,29-didehydronystatin $\mathrm{A}_{1}$, using a fivefold excess of piperidine in DMSO (yield 80\%).

\section{Biology of in vivo antifungal activity}

Animals. Male mice of hybrids of first generation (C57Bl/6xDBA/2)F1 B6D2F1 (weight 20-22 g), received from the Central farm 'Kryukovo' of the Russian Academy of Medical Science (RAMS, Moscow, Russia), were used. Animals were maintained in a vivarium in plastic cages (with hardwood bedding in environmentally controlled conditions: $24 \pm 1{ }^{\circ} \mathrm{C} 12 \mathrm{~h} / 12 \mathrm{~h}$ light/ dark cycle) on a standard diet of bricketed forages with easy access to drinking water (ad libitum). After a 2-week quarantine period, healthy animals were used in experimental work.

Antifungal agents. Solutions of compounds 2, 2a or 2G were prepared 'ex tempore and were kept in dark glass vials to avoid ingress of light. Compound 2G was dissolved in a $5 \%$ neutral sterile glucose solution. The solutions of compounds 2 and 2a were prepared as follows: Dry antibiotic substances $(5 \mathrm{mg})$ were mixed with dry sodium deoxycholate $(4.1 \mathrm{mg})$ in a sterile glass vial. Phosphate buffer $(10 \mathrm{ml})\left(\mathrm{NaH}_{2} \mathrm{PO}_{4}, 1.59 \mathrm{~g} ; \mathrm{Na}_{2} \mathrm{HPO}_{4}, 0.96 \mathrm{~g} ; \mathrm{H}_{2} \mathrm{O} 100 \mathrm{ml}\right)$ was added to the mixture and the suspension was immediately subjected to vigorous shaking for $10 \mathrm{~min}$ until homogeneous suspensions were formed. The obtained suspensions ( $2 \mathrm{ml}$ ) were placed in new sterile glass vials, $6 \mathrm{ml}$ of $5 \%$ neutral sterile glucose solution was added and the resulting solutions $\left(0.125 \mathrm{mg} \mathrm{ml}^{-1}\right)$ were used for i.v. administration. Preparation of the sample of $\mathrm{AmB}$ was also carried out in the same way.

Toxicology. Acute toxicity was studied as it was previously described by Preobrazhenskaya et al. ${ }^{8}$

\section{Study of specific activity of 2 and 2 a on the model of candidosis sepsis of mice}

Maximum tolerated dose and antifungal activity of $\mathbf{2}$ and $\mathbf{2 a}$ compared with $\mathrm{AmB}$ were tested in a mouse model of disseminated candidosis as described in Preobrazhenskaya et al. ${ }^{8}$

The MTD of compound $\mathbf{2}$ or $\mathbf{2 a}$, as well as of AmB, was determined. Antibiotic preparations were singly injected into the tail vein of mice within $1-1.5 \mathrm{~h}$ after the preparation of solutions. The speed of injection did not exceed $0.5 \mathrm{ml} \mathrm{min}{ }^{-1}$. Each antibiotic was used in a range of doses resulting in $0-100 \%$ lethality and a minimum of three intermediate doses. Animals were randomized into groups, each containing six mice. Toxicity-characterizing doses (MTD) were calculated using the method of 'probit analysis' according to Litchfield-Wilcoxon by using the statistical analysis program 'StatPlus-3.5.0.2005' (AnalystSoft Inc., Vancouver, BC, Canada). The results are shown in Table 4.

Animals were infected i.v. with a C. albicans culture at a dose of 1.0 million CFUs per mouse (volume $0.1 \mathrm{ml}$ ). At $30 \mathrm{~min}$ after infection, antifungal agents were introduced i.v. into mice at various doses at a volume of $0.2 \mathrm{ml}$ (at a rate of $0.2 \mathrm{ml}$ per $30 \mathrm{~s}$ ). Each dose was administered daily for 4 days including the day of infection (0, 1, 2 and 3 days). A group of untreated mice (infected in the same way with C. albicans) was used as a control. In addition, there was a 'placebo' group of noninfected animals that were i.v. administered (in the same volume as antifungal agent preparations) with $0.2 \mathrm{ml}$ of phosphate buffer and
$5 \%$ glucose (1:1). No activity was identified in any of the 'placebo' groups. In addition, C. albicans was never detected in noninfected animals.

On the fifth day of the experiment, mice were weighed and killed by cervical dislocation. Thereafter, in sterile conditions, the C. albicans burden of each mouse was determined by counting viable homogenates obtained from kidneys. Kidneys were removed aseptically and weighed, and then pounded in porcelain mortars with sterile corundum. Dilutions of the resulting suspensions were prepared and added onto Petri dishes containing Saburo agar and incubated for $24 \mathrm{~h}$ at a temperature of $35^{\circ} \mathrm{C}$. Developed colonies of C. albicans were then counted and their quantity was calculated on the basis of $1 \mathrm{~g}$ of kidney tissue.

Statistical analysis was carried out using Microsoft Office Excel 2003. Significant distinctions had $P \leqslant 0.05$ when compared using Student's $t$ criterion. The results are shown in Table 4.

\section{Study of specific activity of new polyene antibiotics on the model of candidosis sepsis in leucopenic mice}

Induction of temporary leucopenia. Cyclophosphamide (Biotex, Saransk, Russia) was administrated at a dose $100 \mathrm{mg} \mathrm{kg}^{-1}$ per day, 3 days before $(\mathrm{d}-3)$ and 1 day after $(\mathrm{d} 1)$ infection $(\mathrm{d} 0)$.

Animals were housed in vivariums with three mice in each cage and infected i.v. with a culture of C. albicans (strain 14053 ATCC) at a dose of $3 \times 10^{5}$ CFUs per mouse in a volume of $0.1 \mathrm{ml}$. It is necessary to note that the dose of $C$. albicans remained constant in all experiments. The first i.v. introduction of tested preparations in corresponding doses at a volume of $0.2 \mathrm{ml}$ (with a speed of $0.2 \mathrm{ml}$ per $30 \mathrm{~s}$ ) was carried out $30 \mathrm{~min}$ after infection.

The experiment has been planned in such a manner that, in each experiment, one dose (of $\mathrm{AmB}$ and of tested preparations) was used; each dose was administered daily for 4 days, from the day of infection (0, 1, 2 and 3 days). Each experiment contained a group of untreated mice, a group of mice infected with C. albicans and a group that received cyclophosphamide alone. In addition, there was a group, 'placebo', comprised of intact (noninfected) animals, which were i.v. (in the same volume as medical preparations) injected with $0.2 \mathrm{ml}$ of solvent-phosphate buffer plus $5 \%$ glucose (1:1). Placebos did not show any activity. C. albicans was never detected in noninfected animals.

After the last injection of the tested preparations, mice were weighed and killed by a cervical dislocation. Then, in sterile conditions, C. albicans burdens were determined by viable counting of homogenates from kidneys. Kidneys were removed aseptically and weighed, pounded in porcelain mortars using sterile corundum and suspensions were diluted and poured into Petri dishes containing Saburo agar. The Petri dishes were incubated for $48 \mathrm{~h}$ at a temperature of $35^{\circ} \mathrm{C}$, the number of colonies of $C$. albicans was counted and their quantity on $1 \mathrm{~g}$ of kidney tissue was recalculated. The first dilution was $10^{-1}$. Zero result at this cultivation was accepted for 5 CFUs per g.

Statistical processing was carried out with the help of the computer program Microsoft Office Excel 2003. Significant accepted distinctions had an average value of $P \leqslant 0.05$ when compared using Student's $t$ criterion. Data are presented in Figure 1.

\section{ACKNOWLEDGEMENTS}

This study was supported by the Biosergen AS and the Research Council of Norway. We thank H Sletta and K Degnes for providing polyene macrolide $\mathbf{1}$ (S44HP). We thank Rohn and Haas France SAS company and personally IV Bakhtin for the present of a sample of Amberlite IRA743, TA Loim (Moscow) for excellent technical assistance in the purification of the compounds, NM Maliutina (Moscow) for HPLC analysis and Dr YN Luzikov (Moscow) for NMR spectra.

1 Demain, A. L. \& Sanchez, S. Microbial drug discovery: 80 years of progress. J. Antibiot. 62, 5-16 (2009).

2 De Kruijff, B. \& Demel, R. A. Polyene antibiotic-sterol interactions in membranes of Acholeplasma laidlawii cells and lecithin liposomes. 3. Molecular structure of 
the polyene antibiotic-cholesterol complexes. Biochim. Biophys. Acta. 339, 57-70 (1974).

3 Hac-Wydro, K., Dynarowicz-Łatka, P., Grzybowska, J. \& Borowski, E. N-(1-piperidinepropionyl)amphotericin B methyl ester (PAME) - a new derivative of the antifungal antibiotic amphotericin B: searching for the mechanism of its reduced toxicity. J. Colloid Interface Sci. 287, 476-484 (2005).

4 Slisz, M., Cybulska, B., Mazerski, J., Grzybowska, J. \& Borowski, E. Studies of the effects of antifungal cationic derivatives of amphotericin B human erythrocytes. J. Antibiot. 57, 669-678 (2004).

5 Grzybowska, J., Sowinski, P., Gumieniak, J., Zieniawa, T. \& Borowski, E. N-methyl-N-Dfructosyl amphotericin B methyl ester, new amphotericin B derivative of low toxicity. J. Antibiot. 50, 709-711 (1997).
6 Kazanah, N. \& Hamann, M. T. SPK-843 new antifungal agent. Curr. Opin. Investig. Drugs 6, 845-856 (2005).

7 Bruheim, P. et al. Chemical diversity of polyene macrolides produced by Streptomyces noursei ATCC 11455 and recombinant strain ERD44 with genetically altered polyketide synthase NysC. Antimicrob. Agents Chemother. 48, 4120-4129 (2004).

8 Preobrazhenskaya, M. N. et al. Chemical modification and biological evaluation of new semi-synthetic derivatives of 28,29 -didehydronystatin $A_{1}$ (S44HP), a genetically engineered anti-fungal polyene macrolide antibiotic. J. Med. Chem. 52, 189-196 (2009).

9 Takemoto, K., Yamamoto, Y. \& Ueda, Y. Evaluation of antifungial pharmacodinamic characteristics of ambisome against Candida albicans. Microbiol. Immunol. 50, 579-586 (2006).

Supplementary Information accompanies the paper on The Journal of Antibiotics website (http://www.nature.com/ja) 